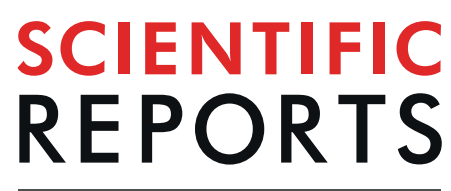

natureresearch

\title{
Pharmacokinetic parameters of ifosfamide in mouse pre- administered with grapefruit juice or naringin
}

\author{
Eduardo Madrigal-Bujaidar ${ }^{1}$, Edilberto Pérez-Montoya², Sandra García-Medina ${ }^{2}$, \\ José Melesio Cristóbal-Luna ${ }^{1}$, José A. Morales-González ${ }^{3}$, Eduardo Osiris Madrigal-Santillán ${ }^{3}$, \\ Rogelio Paniagua-Pérez ${ }^{4}$ \& Isela Álvarez-González $\mathbb{1}^{1^{*}}$
}

Grapefruit juice (GFJ) and naringin when consumed previously or together with medications may alter their bioavailavility and consequently the clinical effect. Ifosfamide (IF) is an antitumoral agent prescribed against various types of cancer. Nevertheless, there is no information regarding its interaction with the ingestion of GFJ or naringin. The aims of the present report were validating a method for the quantitation of IF in the plasma of mouse, and determine if mice pretreated with GFJ or naringin may modify the IF pharmacokinetics. Our HPLC results to quantify IF showed adequate intra and inter-day precision (RSD $<15 \%)$ and accuracy $(\mathrm{RE}<15 \%)$ indicating reliability. Also, the administration of GFJ or naringin increased $C_{\max }$ of IF $22.9 \%$ and $17.8 \%$, respectively, and decreased $T_{\max }$ of IF 19.2 and $53.8 \%$, respectively. The concentration of IF was higher when GFJ $(71.35 \pm 3.5 \mu \mathrm{g} / \mathrm{mL})$ was administered with respect to that obtained in the combination naringin with IF $(64.12 \pm \mu \mathrm{g} / \mathrm{mL})$; however, the time required to reach such concentration was significantly lower when naringin was administered $(p<0.5)$. We concluded that pre-administering GFJ and naringin to mice increased the $T_{\max }$ and decreased the $C_{\max }$ of IF.

Grapefruit juice (GFJ) is a complex mixture formed by a number of compounds that include minerals, vitamins, flavonoids, furanocoumarins and sesquiterpenes, among other chemicals. The juice is known to have nutritional importance as well as to possess a number of biomedical properties, including a strong antioxidant activity, and effects related with the decrease of metabolic syndrome symptoms, digestive problems, and with the improvement of cardiac diseases. Moreover, it has also been reported its effect in the prevention of chronic degenerative diseases, and cancer $^{1-4}$. One of the constituents of GFJ, the flavanone naringin has been identified as the responsible for the bitter flavor of the fruit. The chemical however, has also been found in other citrus fruits and teas, as well as in plants such as cocoa, beans, oregano or tomato ${ }^{5-7}$. Naringin has also been reported to have pharmacologic effects on similar disease conditions to those mentioned for GFJ, besides antibiotic and anti-parasitic properties ${ }^{8,9}$.

Interestingly, both agents (GFJ and naringin) have shown the capacity to modify the pharmacokinetic parameters of numerous medications when ingested together with, or close to the consumption of the juice or of the flavanone. Bailey et al. ${ }^{10}$ were the first group that described such drug interaction, and informed on a significant increase in the bioavailability of felodipine and nifedipine. In the following years, a number of interactions between drugs and GFJ or naringin consumption has been detected presenting alterations of pharmacokinetic parameters. Such interactions have been observed with the use of calcium channel blockers, HMG-CoA reductase inhibitors, immunosuppressant agents, inhibitors of HIV proteases, phosphodiesterase type 5 inhibitors,

${ }^{1}$ Laboratorio de Genética, Escuela Nacional de Ciencias Biológicas, Instituto Politécnico Nacional. Av. Wilfrido Massieu s/n, Col. Zacatenco, Del. Gustavo A. Madero, Ciudad de México, 07738, Mexico. ${ }^{2}$ Laboratorio de Biofarmacia, Departamento de Farmacia, Escuela Nacional de Ciencias Biológicas, Instituto Politécnico Nacional, Av. Wilfrido Massieu s/n, Col. Zacatenco, Del. Gustavo A. Madero, Ciudad de México, 07738, Mexico. ${ }^{3}$ Laboratorio de Medicina de la Conservación, Escuela Superior de Medicina, Instituto Politécnico Nacional. Plan de San Luis y Díaz Mirón s/n, Col. Casco de Santo Tomás, Del. Miguel Hidalgo, Ciudad de México, 11340, Mexico. ${ }^{4}$ Instituto Nacional de Rehabilitación, Servicio de Bioquímica. Av. México-Xochimilco 289, Ciudad de México, 14389, Mexico. *email: isela. alvarez@gmail.com 


\begin{tabular}{|l|l|l|l|}
\hline IF concentration & \multicolumn{2}{|l|}{ R.S.D (\%) } & \multirow{2}{*}{} \\
\cline { 1 - 3 }$(\boldsymbol{\mu} \mathrm{g} / \mathrm{mL})$ & Intra-day & Inter-day & RE (\%) \\
\hline 10 & 11.34 & 14.92 & -4.27 \\
\hline 40 & 8.15 & 9.89 & 14.39 \\
\hline 90 & 2.39 & 7.04 & 12.83 \\
\hline
\end{tabular}

Table 1. HPLC Method for determining ifosfamide (IF) in the plasma of mice. Results on precision and accuracy. The relative standard deviation (RSD) shows the deviation of the usual standard deviation when the mean of the data set is compared. $R S D=\left(\frac{\text { Standard deviation }}{\text { Mean }}\right)(100)$. The $\%$ of the relative error $(\mathrm{RE} \%)$ is a form to express the accuracy of a determination respect to a central tendency $R E=\left(\frac{\text { Observed concentration - Nominal concentration }}{\text { Nominal Concentration }}\right)(100) n=3$.

antihistamine, anthelmintic, and anti-inflammatory drugs ${ }^{10-19}$. The intervention of GFJ and naringin in such processes has been found in various in vitro and in vivo assays, as well as in computational modeling studies. These studies have suggested at least two mechanisms involved to explain the observed effects: the inhibition of intestinal enzymes (mainly CYP3A) to decrease the rate of pre-systemic metabolism, and consequently to increase the bioavailability of the involved drug ${ }^{20,21}$, and alterations in molecular transporters, such as the organic anion-transporting polypeptide 2B1 (OATP2B1), the multidrug-resistant protein sulfotransferases 1 and 3, and the P-glycoprotein transporter ${ }^{22,23}$. An interesting report by Dresser et al. ${ }^{24}$, demonstrated that GFJ is a potent inhibitor of OATP, therefore may modify the absorption of drugs and consequently their bioavailability. Besides, a decrease in drug uptake transport has been generally related with the inhibition of organic anion transporting polypeptides, as well as with the inhibition of the membrane transporters P-glycoprotein esterases and transferases. The transporters are able to pump back some chemicals to the lumen of the enterocyte ${ }^{20,25,26}$. For the present report it seems pertinent to mention that in mouse it has been described the expression of the enzyme CYP3A11, which correspond to the human CYP3A4 representative ${ }^{27}$, and that even though the metabolic differences, pharmacokinetic studies in mouse have human clinical relevance, because mouse most closely approximates the determination of pharmacokinetic measures in humans than other in vivo or in vitro model, showing a linearity response greater than $0.94 \%$ respect to human studies ${ }^{28,29}$.

On the other hand, ifosfamide (IF) is an anticancer agent used for the treatment of various solid tumors, soft tissue sarcoma, and leukaemia ${ }^{30}$. The compound is an oxazaphosphorine prodrug that requires activation by the hepatic cytochrome P450, in particular a 4-hydroxylation catalyzed by CYP3A4, CYPC9 and CYP2B6 enzymes which yields a cytotoxic nitrogen mustard that can react with the DNA molecule to form crosslinks and lead to cell apoptosis ${ }^{31}$. During its metabolic pathway, the CYP2B6 enzyme may also generate the neurotoxic and nephrotoxic compounds, 2 - and 3-dechloroethylifosfamide, respectively ${ }^{32,33}$.

With respect to IF, its nitrogen mustard and conjugates, several transporters related with their uptake and efflux have been described, such as the breast cancer resistance protein and the multidrug resistance associated proteins $^{31}$. Therefore, the involvement of various CYP enzymes in the metabolism of IF, as well as the participation of protein transporters in its absorption, suggest that agents interacting with the antineoplastic may give rise to modifications in its pharmacokinetics, which in turn, may be reflected as alterations in its absorption, distribution, biotransformation and/or excretion ${ }^{31,34}$.

Therefore, considering that knowledge of GFJ and naringin interaction with a variety of drugs may be useful to correct time/dosage of the involved medicament, as well as the absence of information respect to IF, the aim of the present investigation was initially, to validate a method for the quantification of the antineoplastic agent in the plasma of mouse, and subsequently, to determine if mice pretreated with GFJ and/or naringin may modify the IF pharmacokinetics.

\section{Results}

Validation of the HPLC procedure for the quantification of ifosfamide. For this purpose, the linear regression of the peak-area ratios versus concentrations was fitted in the concentration range of $5-100 \mu \mathrm{g} / \mathrm{mL}$. A typical equation of the calibration curve on a validation run was as follows:

$$
y=0.047 x-0.094\left(r^{2}=0.994\right)
$$

where " $y$ " represents the peak-area ratio of the analyte (IF) to the internal standard (CF), and " $x$ " represents the plasma concentration of IF. Good linearity was obtained in this concentration range. Total mean (\% RSD) recoveries were $101.05 \%(8.19 \%), 100.62 \%(0.55 \%)$, and $95.47 \%(2.94 \%)$ for the low, medium, and high QC, respectively. The precision and accuracy values corresponding to low, medium, and high QC are shown in Table 1 . These values were within the acceptable range, and the method was thus judged suitable, accurate and precise. The lower limit of quantification of IF was established as $5 \mu \mathrm{g} / \mathrm{mL}$, with precision of $4.56 \%$, and accuracy of $3.17 \%$.

The results concerning stability tests of IF are shown in Table 2 . These were designed to cover anticipated conditions of handling in the laboratory respect to the IF analysis.

Ifosfamide pharmacokinetic parameters in GFJ and naringin treated mice. The developed and validated method was applied to monitor the IF plasmatic levels in the groups also administered naringin or GFJ. By comparing the IF mean concentrations among the different treatments we observed a clear $C_{\text {max }}$ increase, as well as a reduction in the time required to reach such concentration $\left(T_{\max }\right)$ (Fig. 1). The IF pharmacokinetic analysis of the individual data from the twelve temporal courses was made through a non-compartmental model, therefore, we assumed that values of the seven mice (examined at 2.5, 5, 7.5, 10, 20, 30, and 60 min of exposure) 


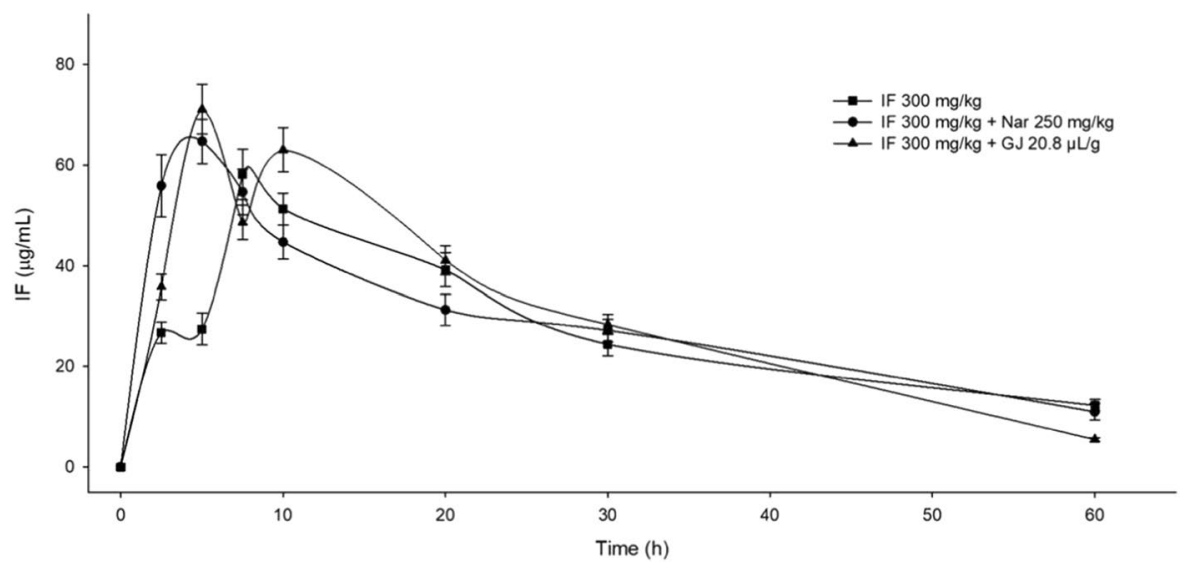

Figure 1. Mean mouse plasmatic concentrations of ifosfamide (IF) respect to time. Mice administered IF, naringin (Nar) plus IF, and grapefruit juice (GFJ) plus IF. Naringin and GFJ were administered $1 \mathrm{~h}$ before IF. Each point represents the mean \pm SEM of the concentration of IF in the plasm of mice at 2.5, 5, 7.5, 10, 20, 30 and $60 \mathrm{~min}$ after its administration.

\begin{tabular}{|c|c|c|c|c|}
\hline \multirow[b]{2}{*}{ Storage conditions } & \multicolumn{2}{|c|}{ Concentration $(\mu \mathrm{g} / \mathrm{mL})$} & \multirow[b]{2}{*}{ RSD (\%) } & \multirow[b]{2}{*}{ RE (\%) } \\
\hline & Added & Found & & \\
\hline \multirow{2}{*}{ Short-term $\left(24 \mathrm{~h}, 25^{\circ} \mathrm{C}\right)$} & 10 & $12.31 \pm 0.68$ & 5.39 & -11.66 \\
\hline & 90 & $100.11 \pm 14.27$ & 14.26 & 0.04 \\
\hline \multirow{2}{*}{ Long-term ( 30 days, $\left.-70^{\circ} \mathrm{C}\right)$} & 10 & $11.17 \pm 0.53$ & 4.77 & -6.18 \\
\hline & 90 & $108.34 \pm 1.64$ & 1.51 & -11.15 \\
\hline \multirow{2}{*}{ Freeze and thaw stability $\left(-70\right.$ to $\left.25^{\circ} \mathrm{C}\right)$} & 10 & $11.16 \pm 0.11$ & 0.99 & -1.82 \\
\hline & 90 & $81.34 \pm 4.99$ & 6.14 & 18.78 \\
\hline
\end{tabular}

Table 2. Stability determination of ifosfamide (IF) under various storage conditions. $R S D=\left(\frac{\text { Standart deviation }}{\text { Average }}\right)(100) \cdot R E=\left(\frac{\text { Observed concentration }- \text { Nominal concentration }}{\text { Nominal Cocentration }}\right)(100) \cdot n=3$.

\begin{tabular}{|l|c|c|c|}
\hline Measured Parameter & IF only $(\mathbf{3 0 0} \mathbf{~ m g} / \mathbf{k g})$ & $\begin{array}{l}\text { Naringin }+\mathbf{I F}(\mathbf{2 5 0} \mathbf{~ m g} / \\
\mathbf{k g}+\mathbf{3 0 0} \mathbf{m g} / \mathbf{k g})\end{array}$ & $\begin{array}{l}\text { GFJ }+\mathbf{I F} \\
\mathbf{( 2 0 . 8} \boldsymbol{\mu L} / \mathbf{g}+\mathbf{3 0 0} \mathbf{~ m g} / \mathbf{k g})\end{array}$ \\
\hline$C_{\max }(\mu \mathrm{g} / \mathrm{mL})$ & $58.08 \pm 5.01$ & $64.12 \pm 4.37^{\mathbf{a}}$ & $71.35 \pm 3.57^{\mathrm{a}}$ \\
\hline$T_{\max }(\mathrm{min})$ & $10.83 \pm 1.28$ & $5 \pm 0.68^{\mathrm{a}}$ & $8.75 \pm 2.05$ \\
\hline$A U C_{0-\infty}\left(\mu \mathbf{g}^{*} \mathrm{~min} / \mathrm{mL}\right)$ & $2110.36 \pm 114.98$ & $2245.40 \pm 211.9$ & $2052.03 \pm 102.33$ \\
\hline$t_{1 / 2}(\mathrm{~min})$ & $23.55 \pm 1.86$ & $26.77 \pm 3.77$ & $16.54 \pm 1.43^{\mathrm{a}}$ \\
\hline
\end{tabular}

Table 3. Pharmacokinetic parameters obtained in the plasma of mice treated with ifosfamide (IF) alone, and with a previous administration of naringin or grapefruit juice (GFJ). Naringin and GFJ were administered $1 \mathrm{~h}$ before IF. $\mathrm{n}=3$. Values represent mean \pm SEM, this were obtained with the WinNonlin 4.0 software. aStatistically significant difference with respect to the value obtained from treated group with IF ( $300 \mathrm{mg} / \mathrm{kg})$. *One way ANOVA, pos hoc Student-Newman-Keuls $(\mathrm{p} \leq 0.05)$. Kruskal-Wallis, pos hoc Student-NewmanKeuls $(\mathrm{p} \leq 0.05)$.

corresponded to a single profile. This approach was appropriate for the statistical analysis of the registered parameters. Table 3 shows a $C_{\max }$ of $58.1 \mu \mathrm{g} / \mathrm{mL}$ for the temporal course of the IF levels; however, when $250 \mathrm{mg} / \mathrm{kg}$ of naringin was orally administered $1 \mathrm{~h}$ before the anticarcinogen $(300 \mathrm{mg} / \mathrm{kg})$, the observed $C_{\max }$ value of IF $(64.1 \mu \mathrm{g} / \mathrm{mL})$ corresponded to a significant increase of $10.4 \%$ respect to the value of IF alone. As regards to the effect of GFJ $(20.8 \mu \mathrm{L} / \mathrm{g})$ administered $1 \mathrm{~h}$ before IF we also found a statistical difference concerning the observed $C_{\max }$, in this case, the value of $71.3 \mu \mathrm{g} / \mathrm{mL}$, represent $22.8 \%$ of a concentration increase for IF. In connection with $T_{\text {max }}$ results, we observed a significant decrease of this parameter with both, naringin and GFJ. In comparison with the time of $10.8 \mathrm{~min}$ for IF, the administration of GFJ plus IF gave rise to $8.7 \mathrm{~min}$ for $T_{\max }$, and with respect to the administration of naringin plus IF the result was of $5 \mathrm{~min}$, a time that was even significant with respect to the value of GFJ plus IF.

The amount of IF absorbed by mouse after its oral administration (represented by the $A U C_{0-\infty}$ ) was equal to $2110.4 \mu \mathrm{g} \times \mathrm{min} / \mathrm{mL}$. The values obtained in the treatments of naringin plus IF, and of GFJ plus IF showed no statistical difference with such value, although a slight tendency of naringin to increase the amount of IF, and of 
GFJ to reduce the $A U C_{0-\infty}$ of IF was observed. Finally, the half-life $\left(t_{1 / 2}\right)$ of IF was $23.5 \mathrm{~min}$. This value decreased $29.8 \%$ when GFJ was administered, however, no change was observed in the case of naringin.

\section{Discussion}

Regarding the study to quantitate the concentration of IF in the plasma of mice, the obtained results suggest that the applied HPLC method was reliable in light of the exactitude and precision of the obtained data, which were within the permitted limits. Besides, the observed data were also reliable because of the confirmation that temperature and storage variations could not be factors that alter the stability of IF. As to GFJ and naringin interaction with IF, it was of interest to note that the $C_{\text {max }}$ values were higher and were reached in shorter times when the two agents (GFJ and naringin) were given before the administration of IF, in comparison with values obtained only with the IF treatment. Interestingly, IF administered alone showed a subtle flattening of the curve followed by a continuous and prolonged elimination phase after reaching the $\mathrm{C}_{\max }{ }^{35,36}$. We think that this behavior does not strictly correspond to a biphasic curve but most probably to the multiple peaks phenomenon, which has usually been reported in pharmacokinetic profiles of molecules examined in blood, by action of the particular formulation of the agent, their physicochemical properties or by physiological factors ${ }^{37}$. In light of the fact that the used IF was pure and not a pharmaceutical form, we consider that its curve behavior was mostly related with physiological factors. Such factors usually include the enterohepatic recycling, and they correspond to the effect of biliary secretions on the elimination of the xenobiotic, followed by its intestinal resorption ${ }^{38}$; the biochemical differences among the various regions of the gastrointestinal tract (GT) (regiospecificity in the concentrations of bile and/ or proteins transport), which are known to be responsible for the progress of absorption on the GT (secondary absorption site), and consequently with the appearance of the site-specific absorption which are represented by various peaks ${ }^{39}$. Another important element refers to the influence of physiological factors of the GT, such as $\mathrm{pH}$, bile salts, phospholipids, and to the presence of other chemicals. These factors are known to determine the speed of transit in the intestine and have direct repercussion on the absorbance process ${ }^{40}$. Thus, our apparent IF biphasic curve could be originated by one or more of the mentioned factors, and therefore be in line with the monophasic curve previously observed for this chemical ${ }^{35}$.

This type of curves has been observed in a number of pharmacokinetic profiles obtained by administering the compounds in conjunction with GFJ; for example, in the case of rosuvostatin, celiprolol, felodipine, and cyclosporine $e^{41-43}$. The explanation for the formation of such curves has relies in the high number of compounds present in GFJ including flavonoids, furanocoumarins, carotenoids and vitamins, chemicals that may interact with the drugs to modify pharmacokinetic parameters ${ }^{44,45}$.

The reported findings indicated that such interaction gave rise to changes in the bioavailability of IF as indicated in the previous section. Regarding $A U C$ data, no changes were determined in the cases of GFJ or naringin; however, the $t_{1 / 2}$ of IF showed a significant decrease but only with the ingestion of GFJ.

GFJ may increase the plasma concentration of drugs, but mainly those that have a higher phase I metabolism, such as IF ${ }^{46}$. Usually, GFJ does not affect the drug's half-life, although there are reports that show a decrease of this parameter ${ }^{47}$. Although CYP3A4 is present in liver and intestinal mucosa, GFJ mainly acts in the intestine because their components are degraded before they can reach the hepatic CYP3A $4^{48}$. Consequently, its effect to increase the plasma level of some substances is due to alterations in the normal intestinal absorption process, once the drug is taken up in the mucosa. IF may be metabolized by hepatic CYP3A4 or pumped back into the intestine lumen by P-glycoprotein and OATP ${ }^{49,50}$. However, when GFJ is administered it may inhibits the activity of these transporters causing an accumulation of IF in the blood (increasing its $C_{\max }$ ). Once in bloodstream, IF reaches the liver, where is metabolized to 4-hydroxyphosphamide by the unchanged liver CYP3A4 (and by the isoforms 2B6, $2 \mathrm{~A} 6,2 \mathrm{C} 8,2 \mathrm{C} 9,2 \mathrm{C} 19$ in a lesser extent $)^{51,52}$. It is important to note that IF metabolism is characterized by being self-induced, that is, IF auto induces its biotransformation by activating the xenobiotic receptor PXR coded by NR1I2 which mediates its autoinduction by the transcriptional upregulation of CYP3A $4^{53}$. Therefore, the concentration increase of IF by GFJ generates a higher concentration of the anticarcinogen in blood, which may increase the transcriptional induction of CYP3A4, self-increasing its own metabolism over time and, consequently, its elimination rate. Therefore, we suggest that an explanation for the IF $C_{\max }$ increase and its $t_{1 / 2}$ decrease its at the intestinal level. At this point, GFJ increases the absorption of non-metabolized IF by inhibiting its intestinal metabolism and pumped back into the intestine lumen. Thus, the high concentration of IF in blood self-induces its own metabolism by CYP3A4 induction and, in consequence, decreases its half-life.

The IF therapeutic potential is well known to include significant DNA damage. On the other hand, naringin has been demonstrated to partially prevent such damage in mouse $\mathrm{e}^{54,55}$. These authors suggested the pertinence of exploring whether the DNA inhibitory effect of naringin could be related with inhibition of the IF absorption/ bioavailability; our present results, however, did not support such possibility. Thus, the antioxidant capacity of naringin remains as the main underlying activity involved in its antigenotoxicity.

At the clinical level, pharmacokinetic changes may have no relevance, as well as moderate or even serious relevance. Respect to the last case, it was observed that a single glass of GFJ ( $250 \mathrm{~mL}$ ), or the consumption of fresh fruit segments might reduce presystemic metabolism and increase bioavailability of a number of drugs. When inhibition of P-glycoprotein occurs, it is possible to observe an increase in the drug's bioavailability related with a decrease of the intestinal or hepatic efflux transport. With respect to the inhibition of organic anion transporting polypeptides, a reduction in the intestinal uptake transport can occur inducing a reduction in the drug's bioavailability $^{56,57}$. These alterations may affect the patient's health depending on the involved medication; for example, the interaction of GFJ with ergotamine may cause gangrene or stroke; with nimodipine systemic hypotension, the interaction with digoxin may cause electrical and mechanical disturbances in the heart, and with atorvastatin, lovastatin, or simvastatin the risk of rhabdomyolysis can increase $\mathrm{e}^{56,58}$. 
Various factors can be involved in the patient's response to the interaction of GFJ or naringin with drugs, such as individual susceptibility and/or the ingested amount of the involved agents. Such conditions may explain the complexity and heterogeneous response of medications respect to the action of GFJ and naringin, a response which goes from various grades of bioavailability modification to the absence of alteration, for example in compounds such as quinine, digoxine, caffeine, and talinolol ${ }^{58-60}$.

\section{Conclusions}

The present study validated for the first time a method for the quantitation of IF in the plasma of mouse, and determined pharmacokinetic changes of such compound in mice pretreated with GFJ or naringin. Regarding the second objective, our results showed modifications in the $C_{\max }$ and $T_{\max }$ of IF. The observed changes, however, do not suggest clinical hazards to patients consuming GFJ in moderate amounts. Nevertheless, in order to reach a definite conclusion it should be advisable to further extent the study using other experimental conditions, including the time and duration of GFJ and naringin administration, the doses tested, and the sampling times.

\section{Methods}

Chemicals and animals. The compounds IF and cyclophosphamide (CF, internal standard) (USP grade) were obtained from Sanfer Laboratories (Mexico City, Mexico). Naringin (4',5,5-trihdroxy-flavanone-7-rhamnoglucoside), acetonitrile and triethylamine were purchased from Sigma-Aldrich Chemicals Co. (St. Louis, Mo. USA). Methanol (HPLC grade) and phosphate salts were purchased from J.T. Baker Chemicals (Mexico City, Mexico). GFJ was freshly squeezed fruit, Citrus paradisi Macfad. var. Ruby red, cultivated in a pesticide free field in Albeciras, Veracruz, $400 \mathrm{~km}$ south-west of Mexico City.

The antineoplastic IF and CF were dissolved in methanol to prepare a standard concentration of $1 \mu \mathrm{g} / \mu \mathrm{L}$ in each case. Also, phosphate buffer solutions $(0.01 \mathrm{~N}$, and $0.025 \mathrm{~N})$ were prepared and adjusted to $\mathrm{pH}$ 4.0.

The experimental protocol in mice was approved by the Committee of Ethics and Biosecurity of the National School of Biological Sciences. We used ICR male mice of $25 \mathrm{~g}$ obtained from Biotinox (Mexico City, Mexico) which were housed in polypropylene cages at $22 \pm 2{ }^{\circ} \mathrm{C}, 50-60 \%$ relative humidity, and under a $12 \mathrm{~h}$ light-dark cycle. They were fed with laboratory animal feed (Rodent Lab Chow 5001, Purina) and purified water. Besides, all methods were performed in accordance with the relevant guidelines and regulations.

Validation of the HPLC procedure for the quantification of ifosfamide. The analytical method was validated according to criteria established by the National norm (NOM-177-SSA1-1998) and International norms (ISO/IEC 25:1990). Mouse IF-free plasma was spiked with IF solutions to obtain a calibration curve at concentrations of 5, 20,30,50 and $100 \mu \mathrm{g} / \mathrm{mL}$. Similarly, quality control samples were prepared at low, medium, and high concentration levels $(10,40$, and $90 \mu \mathrm{g} / \mathrm{mL})$. These were employed to determine absolute recovery, as well as intra- and inter-day precision and accuracy. Precision was expressed by relative standard deviation (RSD), and accuracy as relative error (RE). The intra- and inter-day precision was required to be below $15 \%$, and the accuracy to be within $\pm 15 \%$.

The lower limit of quantification (LLOQ) was determined in five replicates, and corresponded to the lowest concentration of the calibration curve that could be measured with acceptable accuracy and precision. The precision should be equal or less than $20 \%$ and accuracy should be within $\pm 20 \%$.

The stability of IF in the plasma of mouse was assessed by analyzing (in triplicate) plasma samples at concentrations of 10 and $90 \mu \mathrm{g} / \mathrm{mL}$, which were exposed to different conditions (time and temperature). The short-term stability was determined after the exposure of the spiked samples to room temperature for $24 \mathrm{~h}$. The long-term stability was evaluated after storage of the standard spiked plasma samples at $-70^{\circ} \mathrm{C}$ for 30 days. The freeze/thaw cycle stability was assessed after two complete freeze/thaw cycles $\left(-70\right.$ to $\left.25^{\circ} \mathrm{C}\right)$ on consecutive days. The analytes were considered to be stable in plasma when $85-115 \%$ of the initial concentrations were found.

Chromatography conditions for the study were as follows: the mobile phase consisted of acetonitrile, potassium phosphate buffer $0.025 \mathrm{M}$ at $\mathrm{pH} 4.0$, and triethylamine $(12: 88: 0.025, \mathrm{v} / \mathrm{v})$ with a final $\mathrm{pH}$ of 6.2 . The flow-rate was $1.2 \mathrm{~mL} / \mathrm{min}$. The analytical column was operated at ambient temperature. The HPLC system consisted of a Beckman System Gold, 128 Solvent Module with ultra-violet detection at $200 \mathrm{~nm}$. We used a $3.5 \mu \mathrm{m}$ Xterra RP-8 $(4.6 \times 150 \mathrm{~mm})$ column. Data were collected by the HPLC system and transferred to a Dell Pentium computer.

Mouse IF pharmacokinetic study. For the study, 7 groups with 12 animals each were intragastrically (ig) administered with $300 \mathrm{mg} / \mathrm{kg}$ of IF. Then, we obtained $1 \mathrm{~mL}$ of blood by cardiac puncture at 2.5, 5, 7.5, 10, 20, 30, and $60 \mathrm{~min}$ post-administration.

Blood samples were immediately centrifuged at $3500 \mathrm{rpm}$. Aliquots of $250 \mu \mathrm{L}$ were stored at $-70{ }^{\circ} \mathrm{C}$ until the quantification of IF plasmatic concentrations was carried out.

Ifosfamide pharmacokinetic parameters in GFJ and naringin treated mice. Besides in our research, 7 groups with 12 animals each were ig administered with naringin $(250 \mathrm{mg} / \mathrm{kg})$ to evaluate its influence on the concentration/time profiles of IF, a chemical that was ig administered $60 \mathrm{~min}$ later $(300 \mathrm{mg} / \mathrm{kg})$. Seven other groups were ig administered GFJ $(20.8 \mu \mathrm{L} / \mathrm{g})$ and $60 \mathrm{~min}$ later ig treated with $300 \mathrm{mg} / \mathrm{kg}$ of IF. In both assays, we obtained blood samples at $2.5,5,7.5,10,20,30$, and $60 \mathrm{~min}$ post-administration. With the indicated design we examined the influence of GFJ or naringin on the concentration/time profiles of IF.

For the blood treatment, after thawing, we added $250 \mu \mathrm{L}$ of the internal standard (CF) to each sample, after which the plasma was deproteinized with methanol 1:1.5 (plasma-methanol), and centrifuged at $3500 \mathrm{rpm}$ for $10 \mathrm{~min}$. Subsequently, we transferred $450 \mu \mathrm{L}$ of the supernatant to an Eppendorf tube containing $550 \mu \mathrm{L}$ of phosphate buffer $0.01 \mathrm{~N}, \mathrm{pH} 4.0$. The solution was activated with $1 \mathrm{~mL}$ of methanol plus $1 \mathrm{~mL}$ of phosphate buffer $0.01 \mathrm{~N}, \mathrm{pH} 4.0$, and loaded to a Bond Elut- $\mathrm{CH}$ cartridge under reduced pressure. The cartridge was washed with 
$1 \mathrm{~mL}$ of acetonitrile plus phosphate buffer $0.01 \mathrm{~N}, \mathrm{pH} 4.0(10-90 \%)$ and it was eluted with $500 \mu \mathrm{L}$ of acetonitrile plus phosphate buffer $0.025 \mathrm{~N}, \mathrm{pH} 4.0(40-60 \%)$. A volume of $20 \mu \mathrm{L}$ were injected in the stabilized HPLC system.

Pharmacokinetic data and statistical assays. The pharmacokinetic parameters of IF and their interaction with naringin or GFJ were calculated by non-compartmental assessment of data using the computer program WinNonlin (V4.0, Pharsight, Mountain View, CA, USA). The maximum plasma concentrations $\left(C_{\max }\right)$ and their time of occurrence $\left(T_{\max }\right)$ were both obtained directly from the measured data. The area under the plasma concentration-time curve, from time zero to the time of the last measurable concentration $\left(A U C_{0-t}\right)$ was calculated with the linear trapezoidal method. $A U C_{0-\infty}$ was calculated $A U C_{0-t}+C_{t} / \lambda_{z}$, where $C_{t}$ is the last measurable concentration and $\lambda_{z}$ the constant rate of terminal elimination. The corresponding half-life elimination $\left(t_{1 / 2}\right)$ was then calculated as $0.693 / \lambda_{z}$. The results corresponding to $C_{\max }$ were statistically analyzed with the ANOVA and the Student-Newman-Keuls tests. With respect to $A U C_{0-t}, T_{\max }$, and $t_{1 / 2}$ the analysis was made with the Kruskal-Wallis test.

Received: 2 August 2019; Accepted: 24 October 2019;

Published online: 12 November 2019

\section{References}

1. Yu, J., Ghiviriga, I., Buslig, B. S. \& Cancalon, P. A strong antioxidant isolated from grapefruit juice retentate. Food Sci. Technol. 41, 420-424 (2008)

2. Castro-Vazquez, L. et al. Bioactive Flavonoids, Antioxidant Behaviour, and Cytoprotective Effects of Dried Grapefruit Peels (Citrus paradisi Macf.). Oxid Med Cell Longev. 2016, 8915729 (2016).

3. Madrigal-Bujaidar, E., Martino, L., García, K., Garcia, S. \& Álvarez, I. Grapefruit juice suppresses azoxymethane-induced colon aberrant crypt formation and induces antioxidant capacity in mice. Asian Pac. J. Cancer Prev. 14, 6851-6685 (2013).

4. Mouly, S., Morgand, M., Lopes, A., Lloret-Linaringines, C. \& Bergmann, J. F. Interactions médicaments-aliments en médecine interne: quels messages pour le clinicien? Rev. Med. Interne. 36, 530-539 (2015).

5. Kirakosyan, A. et al. Interactions of antioxidants isolated from tart cherry (Prunus cerasus) fruits. Food Chemistry 122, 78-83 (2010).

6. Goliomytis, M. et al. The Influence of Naringin or Hesperidin Dietary Supplementation on Broiler Meat Quality and Oxidative Stability. PLoS One. 10(10), e0141652 (2015).

7. European Food Safety Authority. Scientific opinion on the safety and efficacy of naringiningin when used as a sensory additive for all animal species. EFSA J. 9, 2416-27 (2011).

8. Lakshmi, V. et al. Antifilarial activity in vitro and in vivo of some flavonoids tested against Brugia malayi. Acta Trop. 116, 127-133 (2010).

9. Céliz, G., Daz, M. \& Audisio, M. C. Antibacterial activity of naringiningin derivatives against pathogenic strains. J. Appl. Microbiol. 111, 1364-1372 (2011)

10. Bailey, D. G., Spence, J. D., Munoz, C. \& Arnold, J. M. Interaction of citrus juices with felodipine and nifedipine. Lancet. 337, 268-269 (1991)

11. Benton, R., Honig, P., Zamani, K., Cantilena, L. \& Woosley, R. Grapefruit juice alters terfenadine pharmacokinetics, resulting in prolongation of repolarization on the electrocardiogram. Clin. Pharmacol. Ther. 59, 383-388 (1996).

12. Ku, Y., Min, D. \& Flanigan, M. Effect of grapefruit juice on the pharmacokinetics of microemulsion cyclosporine and its metabolite in healthy volunteers: does the formulation difference matter? J. Clin. Pharmacol. 38, 959-965 (1998).

13. Jáuregui-Garrido, B. \& Jaáuregui-Lobera, I. Interactions between antihypertensive drugs and food. Nutr. Hosp. 27(5), 1866-1875 (2012).

14. Kupferschmidt, H. H., Fattinger, K. E., Ha, H. R., Follath, F. \& Krähenbühl, S. Grapefruit juice enhances the bioavailability of the HIV protease inhibitor saquinavir in man. Br. J. Clin. Pharmacol. 45, 355-359 (1998).

15. Castro, N. et al. Interaction between grapefruit juice and praziquantel in humans. Antimicrob. Agents Chemother. 46, 1614-1616 (2002).

16. Jetter, A. et al. Effects of grapefruit juice on the pharmacokinetics of sildenafil. Clin. Pharmacol. Ther. 71, 21-29 (2002).

17. Schwartz, B. G. \& Kloner, R. A. Drug interactions with phosphodiesterase-5 inhibitors used for the treatment of erectile dysfunction or pulmonary hypertension. Circulation. 122(1), 88-95 (2010)

18. Zargar, S., Al-Majed, A. A. \& Wani, T. A. Potentiating and synergistic effect of grapefruit juice on the antioxidant and antiinflammatory activity of aripiprazole against hydrogen peroxide induced oxidative stress in mice. BMC Complement Altern Med. 18(1), $106(2018)$

19. Uesawa, Y., Takeuchi, T. \& Mohri, K. Integrated analysis on the physicochemical properties of dihydropyridine calcium channel blockers in grapefruit juice interactions. Curr. Pharm. Biotechnol. 13, 1705-1717 (2012).

20. Hanley, M. J., Cancalon, P., Widmer, W. W. \& Greenblatt, J. The effect of grapefruit juice on drug disposition. Expert Opin Drug Metab Toxicol. 7, 267-286 (2011).

21. Basheer, L. \& Kerem, Z. Interactions between CYP3A4 and dietary polyphenols. Oxid. Med. Cell Longev. 2015, 1-15 (2015).

22. Shirasaka, Y., Suzuki, K., Shichiri, M., Nakanishi, T. \& Tamai, I. Intestinal absorption of HMG-CoA reductase inhibitor pitavastatin mediated by organic anion transporting polypeptide and P-glycoprotein/multidrug resistance 1. Drug Metab. Pharmacokinet. 26, $171-179(2011)$

23. Akamine, Y. et al. The change of pharmacokinetics of fexofenadine enantiomers through the single and simultaneous grapefruit juice ingestion. Drug Metab. Pharmacokinet. 30, 352-357 (2015).

24. Dresser, G. K. et al. Fruit juices inhibit organic anion transporting polypeptide-mediated drug uptake to decrease the oral availability of fexofenadine. Clin Pharmacol Ther. 71(1), 11-20 (2002).

25. Dahan, A. \& Altman, H. Food-drug interaction: grapefruit juice augments drug bioavailability-mechanism, extent and relevance. Eur. J. Clin. Nutr. 58, 1-9 (2004)

26. Pirmohamed, M. Drug-grapefruit juice interactions: two mechanisms are clear but individual responses vary. BMJ. 7(346), f1 (2013).

27. Sukkummee, W., Jittisak, P., Wonganan, P., Wittayalertpanya, S. \& Chariyavilaskul, P. Leelahavanichkul, The prominent impairment of liver/intestinal cytochrome P450 and intestinal drug transporters in sepsis-induced acute kidney injury over acute and chronic renal ischemia, a mouse model comparison. Ren Fail. 41(1), 314-325 (2019).

28. Wong, H. et al. Antitumor activity of targeted and cytotoxic agents in murine subcutaneous tumor models correlates with clinical response. Clin Cancer Res. 18(14), 3846-55 (2012).

29. Spilker, M. E. et al. Found in translation: Maximizing the clinical relevance of nonclinical oncology studies. Clin Cancer Res. 23(4), 1080-1090 (2017). 
30. Lin-Kun, L., Po-Min, C., Cheng-Hwai, T., Jin-Hwang, L. \& Chueh-Chuan, Y. Ifosfamide-induced Fanconi's syndrome. J. Cancer Res. Practice. 1, 46-49 (2014).

31. Zhang, J., Tian, Q., Chan, S. Y., Duan, W. \& Zhou, S. Insights in to oxazaphosphorine resistance and possible approaches to its circumvention. Drug Resist. Update. 8, 271-277 (2005).

32. Ciarimboli, G. et al. New clues for nephrotoxicity induced by ifosfamide: preferential renal uptake via the human organic cation transporter 2. Mol. Pharm. 8, 270-279 (2011).

33. Li, F. et al. Comparative metabolism of cyclophosphamide and ifosfamide in the mouse using UPLC-ESI-QTOFMS-based metabolomics. Biochem. Pharmacol. 80, 1063-1074 (2010).

34. Harmsen, S., Meijerman, I., Beijnen, J. H. \& Schellens, J. H. The role of nuclear receptors in pharmacokinetic drug-drug interactions in oncology. Cancer Treat Rev. 33, 369-380 (2007).

35. Xiong, J., Zhao, G., Yang, S. \& Chen, J. Efficacy, tolerability and pharmacokinetic impact of aprepitant in sarcoma patients receiving ifosfamide and doxorubicin chemotherapy: a randomized controlled trial. Adv. Ther. 36, 355-364 (2019).

36. Mathijssen, R. H. et al. Clinical pharmacokinetics and metabolism of irinotecan (CPT-11). Clin. Cancer Res. 7, 2182-2194 (2001).

37. Davies, N. M., Takemoto, J. K., Brocks, D. R. \& Yáñez, J. A. Multiple peaking phenomena in pharmacokinetic disposition. Clin. Pharmacokinet. 49, 351-377 (2010).

38. Roberts, M. S., Magnusson, B. M., Burczynski, F. J. \& Weiss, M. Enterohepatic circulation: physiological, pharmacokinetic and clinical implications. Clin. Pharmacokinet. 41, 751-790 (2002).

39. Reynolds, K. S. et al. Effect of pancreatic-biliary secretions and GI transit time on the absorption and pharmacokinetic profile of ranitidine in humans. Pharm. Res. 15, 1281-1285 (1998).

40. Staveris, S. et al. Evidence for a second site of absorption of veralipride in the human small intestine: use of a new drug delivery telemetric shuttle. Arzneimittelforschung. 44, 1068-1072 (1994).

41. Kashihara, Y. et al. Small-dosing clinical study: pharmacokinetic, pharmacogenomic (SLCO2B1 and ABCG2), and interaction (atorvastatin and grapefruit juice) profiles of 5 probes for OATP2B1 and BCRP. J. Pharm. Sci. 106, 2688-2694 (2017).

42. Goosen, T. C. et al. Bergamottin contribution to the grapefruit juice-felodipine interaction and disposition in humans. Clin. Pharmacol. Ther. 76, 607-617 (2004).

43. Edwards, D. J. et al. 6', $7^{\prime}$-Dihydroxybergamottin in grapefruit juice and Seville orange juice: effects on cyclosporine disposition, enterocyte CYP3A4, and P-glycoprotein. Clin, Pharmacol. Ther. 65, 237-244 (1999).

44. Bailey, D. G. et al. Grapefruit-felodipine interaction: effect of unprocessed fruit and probable active ingredients. Clin Pharmacol Ther. 68(5), 468-77 (2000).

45. Cristóbal-Luna, J. M., Álvarez-González, I., Madrigal-Bujaidar, E. \& Chamorro-Cevallos, G. Grapefruit and its biomedical, antigenotoxic and chemopreventive properties. Food Chem Toxicol. 112, 224-234 (2018).

46. Lowenberg, D. et al. PharmGKB summary: ifosfamide pathways, pharmacokinetics and pharmacodynamics. Pharmacogenet Genomics. 24(2), 133-8 (2014).

47. Sridharan, K. \& Sivaramakrishnan, G. Interaction of Citrus Juices with Cyclosporine: Systematic Review and Meta-Analysis. Eur J Drug Metab Pharmacokinet. 41(6), 665-673 (2016).

48. Kane, G. C. \& Lipsky, J. J. Drug-grapefruit juice interactions. Mayo Clin Proc. 75(9), 933-42 (2000).

49. Honda, Y. et al. Effects of grapefruit juice and orange juice components on P-glycoprotein- and MRP2-mediated drug efflux. $\mathrm{Br} \mathrm{J}$ Pharmacol. 143(7), 856-64 (2004).

50. König, J., Müller, F. \& Fromm, M. F. Transporters and drug-drug interactions: important determinants of drug disposition and effects. Pharmacol Rev. 65(3), 944-66 (2013).

51. Chugh, R. et al. Assessment of ifosfamide pharmacokinetics, toxicity, and relation to CYP3A4 activity as measured by the erythromycin breath test in patients with sarcoma, Cancer. 1;109(11): 2315-22 (2007).

52. Zhang, J. et al. Metabolism and transport of oxazaphosphorines and the clinical implications. Drug Metab Rev. 37(4), 611-703 (2005).

53. Wang, D., Li, L., Fuhrman, J., Ferguson, S. \& Wang, H. The role of constitutive androstane receptor in oxazaphosphorine-mediated induction of drug-metabolizing enzymes in human hepatocytes. Pharm Res. 28(8), 2034-44 (2011).

54. Álvarez-González, I., Madrigal-Bujaidar, E., Dorado, V. \& Espinosa-Aguirre, J. J. Inhibitory effect of naringin on the micronuclei induced by ifosfamide in mouse, and evaluation of its modulatory effect on the Cyp3a subfamily. Mutat. Res. 480-481, 171-178 (2001).

55. Álvarez-González, I., Madrigal-Bujaidar, E. \& Sánchez, V. Y. Inhibitory effect of grapefruit juice on the genotoxic damage induced by ifosfamide in mouse. Plant Foods Hum. Nutr. 65, 369-373 (2010).

56. Bailey, D. G. \& Dresser, G. K. Interactions between grapefruit juice and cardiovascular drugs. Am. J. Cardiovasc. Drugs. 4, 281-297 (2004).

57. Bressler, R. Grapefruit juice and drug interactions. Exploring mechanisms of this interaction and potential toxicity for certain drugs. Geratrics. 61, 12-18 (2006).

58. Becquemont, L. et al. Effect of grapefruit juice on digoxin pharmacokinetics in humans. Clin. Pharmacol. Ther. 70, 311-316 (2001).

59. Ho, P. C., Clacroft, S. C., Coville, F. \& Wanwimolruk, S. Grapefruit juice has no effect on quinine pharmacokinetics. Eur. J. Clin. Pharmacol. 55, 393-398 (1999).

60. Nguyen, M. A., Staubach, P., Tamai, I. \& Langguth, P. High-dose short-term administration of naringin did not alter talinolol pharmacokinetics in humans. Eur J Pharm Sci. 68, 36-42 (2015).

\section{Author contributions}

Isela Álvarez-González and Eduardo Madrigal-Bujaidar: designed the research and wrote the manuscript. Edilberto Pérez-Montoya and Sandra García Medina: acquisition e interpretation of data. José Melesio Cristóbal Luna and Rogelio Paniagua-Pérez: made the experimental methods and the elaboration of all figures of the manuscript. José A. Morales-González and Eduardo Osiris Madrigal-Santillán: made the statistical analysis and substantively revised the manuscript. All the authors have approved the submitted version.

\section{Competing interests}

The authors declare no competing interests.

\section{Additional information}

Correspondence and requests for materials should be addressed to I.Á.-G.

Reprints and permissions information is available at www.nature.com/reprints.

Publisher's note Springer Nature remains neutral with regard to jurisdictional claims in published maps and institutional affiliations. 
(c) (i) Open Access This article is licensed under a Creative Commons Attribution 4.0 International License, which permits use, sharing, adaptation, distribution and reproduction in any medium or format, as long as you give appropriate credit to the original author(s) and the source, provide a link to the Creative Commons license, and indicate if changes were made. The images or other third party material in this article are included in the article's Creative Commons license, unless indicated otherwise in a credit line to the material. If material is not included in the article's Creative Commons license and your intended use is not permitted by statutory regulation or exceeds the permitted use, you will need to obtain permission directly from the copyright holder. To view a copy of this license, visit http://creativecommons.org/licenses/by/4.0/.

(C) The Author(s) 2019 